\title{
De los nuevos entramados tecnosociales: emergencias políticas y educativas
}

\author{
About new techno-social networks: political and \\ educational emergencies
}

Rocío Rueda Ortiz

\section{Resumen}

El presente artículo es producto de las reflexiones devenidas de una investigación cualitativa realizada en Colombia, con colectivos contraculturales que usan intensivamente tecnologías de la información y la comunicación. Se analizan los hallazgos en relación con nuevas formas de compartir y diseminar conocimientos, y novedosas formas de organización social y política que configuran una práctica social educativa expandida. Dichas prácticas tecnosociales se observan como potenciales formas de resistencia a modelos homogeneizantes y dominantes de la cultura y la política, y muestran formas alternativas de comunidad y de creación de conocimientos. Sin embargo, es una novedad que se observa en tensión con las ambiguas expresiones de poder y desigualdad que, en distintos niveles, conviven en estos colectivos.

\section{Palabras clave:}

Cibercultura, educación, política, comunidad.

\section{Abstract}

This article is based on a qualitative research done with five countercultural groups in Colombia, which intensively use information and communication technologies. The results are analyzed in relation to new ways to share and disseminate knowledge and new forms of social and political organization. They are comprehended as an expanded social educative practice. These technosocial practices are considered as ways of being resistant against dominant and homogenizing political and cultural models. They also show alternative forms of community and knowledge. Nevertheless, it is a novelty observed in relation to the power and inequality that exist in those collectives.

\section{Keywords:}

Ciberculture, education, politics, community.

Artículo recibido el 20 de mayo de 2010 y aprobado el 28 de marzo de 2011

1 Docente-investigadora. Doctorado Interinstitucional en Educación. Grupo de investigación Educación y Cultura Política de la Universidad Pedagógica Nacional. Bogotá, Colombia. Correo-e: rruedaortiz@yahoo.com 


\section{Presentación}

\section{El nuevo socius: sociedad, tecnologías y política}

Si este mundo no estuviera recorrido sin cesar por los movimientos convulsivos de seres que se buscan unos a otros...

George Bataille

Partimos de reconocer, como lo han señalado en gran parte la sociología y antropología de la cultura contemporánea, que nuestros marcos de referencia tradicionales y modernos están siendo interpelados ante la emergencia de nuevas formas de lo social y sus modos de generación de vínculos, de conformación de comunidades y de prácticas sociales donde, por cierto, las tecnologías de la información y la comunicación están jugando un papel catalizador. En este contexto, es de nuestro interés analizar cómo experiencias singulares y colectivas, en interacción con diversas tecnologías, están configurando entramados tecnosociales de otras formas de compartir el saber, nuevos modos de estar y actuar juntos, esto es, otras formas de vida.

Para ello, si bien reconocemos que las teorías de la acción colectiva y de los movimientos sociales abren la posibilidad de comprender otras formas de la política al introducir distintos protagonistas y prácticas democráticas alternativas a las convencionales, así como una crítica al modelo específico de racionalidad desarrollado por la modernidad, a nuestro modo de ver éstas han observado a los actores colectivos dispuestos alrededor de una identidad -en cierta forma homogénea- lo cual permite organizar sus luchas políticas y culturales. Pero en nuestra interacción con diferentes colectivos, a pesar de poder integrarse en una categoría como "contraculturales", y aún en lo que se conoce como movimiento social, sus prácticas sociales no "encajan" o lo hacen de manera parcial en dicha conceptualización. Éstas parecen ser más ambiguas y resbaladizas.

De ahí que preferimos acudir a una conceptualización desde la subjetividad y el poder, tal y como lo han señalado los postestructuralistas como
Foucault y feministas de la ciencia y la tecnología como Haraway. Esta idea de subjetividad híbrida, cyborg, descansa en el intento de superar la visión arrogante unitaria del sujeto para comprender la diferencia, y con ella, las diversas posiciones de sujeto. Esto es "la redefinición no esencialista de los procesos identitarios y el reconocimiento de que están atravesados por relaciones de poder/resistencia, resalta el carácter no homogéneo ni transparente de la identidad" (Flórez, 2004, p. 27), y por lo tanto, también la heterogeneidad de los sujetos sociales.

Sí, se trata de un mundo extraño poblado de una multiplicidad de singularidades y potencialidades. Por ello, consideramos que el concepto de multitud que sigue el camino de Spinoza, como la han caracterizado Negri y Hardt (2000) y Lazzarato (2006), nos puede ser de utilidad aquí para comprender que, si bien este socius es una energía social inestable y volátil, se constituye en voz colectiva que hace resistencia al orden político y cultural con una potencialidad política insospechada. Pero dado que se trata de una política que no es la convencional, representada en partidos, estos autores acuden al término "política menor" para destacar con ello que no se trata de aquella de los proyectos de largo plazo, de clase, y que tampoco responde a la masa o al pueblo. La multitud no es ni el individuo, ni el colectivo o grupo, es una tensión entre ambos y una multiplicidad de singularidades. La multitud articula afectos y experiencias, que son la base para la acción política. Es algo situado en medio, es múltiple y al mismo tiempo conforma un cuerpo singular constituido de diversos intereses, experiencias, afectos y relaciones, sin una unidad homogénea. La relacionalidad y la cooperación establecen lo común que a su vez enfrenta el reto político de la diferencia. Sin embargo, esta multitud es también impredecible e inestable, y creemos, tiene el reto de enfrentar críticamente las desigualdades y ejercicios de poder que internamente le habitan. Algunas de sus expresiones son los movimientos sociales, las movilizaciones a través de tecnologías móviles o digitales y los colectivos de arte en la red, entre otros.

Derivado de los "modos de lo común", y de compartir el saber y habitar el mundo, es que interesa 
comprender el fenómeno educativo como una práctica social expandida, que se está produciendo en el encuentro entre nuevas sensibilidades que enfrentan una heterogeneidad simbólica y un estallido de lo social, y de tecnologías que son, no sólo los medios privilegiados de producción actual ${ }^{2}$, sino, a su vez, novedosos dispositivos de densidad simbólica, acción a distancia, lenguajes de la hipermedialidad, interactividad y conectividad. Para nosotros, las tecnologías se integran y entremezclan en la esfera social, en tanto son incorporadas a valores, prácticas sociales e infraestructuras materiales de sujetos individuales y colectivos, que están situados y que les otorgan sentido. De ahí que veamos, además, en dichas tecnologías, unos dispositivos catalizadores de procesos de socialización y de configuración de subjetividades que, por acción de la agencia humana, devienen en políticas.

Sin embargo, esta nueva condición de la experiencia subjetiva -individual y colectiva-requiere que estemos alertas frente a ciertos determinismos sociales y tecnológicos que sobredimensionan los alcances, tanto de las tecnologías como de los movimientos y colectivos, y sugieren que, por ejemplo, conectividad significa inmediatamente colectividad y democratización. Pero tampoco podemos subestimar la complejidad de este socius ${ }^{3}$ que se enfrenta siempre a un juego de posibilidades que van desde de cooperación y creatividad social, hasta novedosas formas de dominación y captura del deseo para hacerlo útil al capital. Tal y como lo ha mostrado críticamente, por ejemplo, el trabajo de Juliana Flórez (2004) sobre los movimientos sociales, no se

2 Esto implica que las tecnologías están también al servicio de una orientación instrumental de la acción y prácticas de administración, control y gestión empresarial propias del actual sistema productivo, desde donde se privilegian tanto relaciones individualistas como el trabajo colaborativo y en equipo, en aras de una mayor producción del capital, en un contexto de intensificación del ritmo de vida social y el desplazamiento de la reflexión y de la interacción social por la competitividad.

3 Acudimos a esta expresión del latín, socius, para retomar un sentido original: la palabra sociedad se comenzó a usar en español entre 1220 y 1250 , y viene del latín societas que significa 'compañía' y ésta, a su vez, del latín socius que significa 'compañero'. Significado que resuena con la fuerza que hoy el afecto y la amistad tienen en las formas de interacción social, política y educativa que más adelante se describirán. puede pretender evitar observar las desigualdades que persisten aún en movimientos de reivindicación de la diferencia, equidad y justicia social.

Asimismo en esta nueva condición de lo social, por más hipertecnologizada que esté, no se puede omitir el hecho de que las fronteras espaciales y los territorios siguen siendo motivo de conflictos, y que por lo tanto las colectividades también se las tienen que ver con los recursos materiales y el poder. Esto significa que, en nombre de cierta euforia por las redes sociotecnológicas, no podemos desmaterializar los sujetos que las constituyen, sus historias y las diferentes maneras y fuerzas de poder con las que deben lidiar.

Es por ello que la pregunta por lo común tiene un sentido político acuciante hoy, pues en medio de nuevos y desconocidos espacios de libertades, somos responsables de relaciones siempre amenazadas y frágiles. Son tiempos en los que se afirma la individualidad (Beck, 2001; Bauman, 2002), tiempos de destradicionalización y desanclaje (Giddens, 1994), de permanente toma de decisiones y búsqueda de autonomía en la cotidianidad, de aceleración del espacio-tiempo (Virilio, 2005). Adicionalmente, para nosotros se trata de un común que no es "nada común", y que, por el contrario, está hecho de multiplicidades, heterogeneidad y diferencia. Un común que no requiere un contrato social que le dé unidad u homogeneidad, y que hace uso de los nuevos repertorios tecnológicos como una manera de evitar "representaciones" o "intermediarios" y ejercer una política directa en esferas micro y macro.

Ahora bien, en resonancia con estas formas contemporáneas de la política, encontramos en Boaventura de Sousa (2003, pp. 82 y ss.) un aporte complementario cuando nos propone retomar el principio de comunidad que acabamos de mencionar y que para Sousa está ligado con las formas de (auto) regulación y la racionalidad estético-expresiva, vinculada a los procesos de emancipación. El campo de la racionalidad estético-expresiva desplegado en conceptos como placer, autoría y artefactualidad discursiva, tiene un gran potencial para comprender prácticas sociales mediadas tecnológicamente, donde el decir, la expresión, la voz pro- 
pia, los lenguajes de la multiplicidad, de la autoría compartida, distribuida, nos permiten pensar otros modos de estar con, de estar allí, de ser un nosotros, aunque éste sea provisional y contingente.

Estas dos dimensiones, común(idad) y racionalidad estético expresiva, se convierten a su vez en el contexto y pretexto para pensar la educación como una práctica social expandida, donde la expresión, la conquista de la palabra, el reconocimiento de subjetividades otras y la configuración de subjetividades libres o serviles, son asuntos de primer orden. En consecuencia, diremos con Freire, que la educación es, ante todo, una práctica política. Por ello, si la educación la pensamos como una posibilidad de emancipación, la pregunta por cómo vivir juntos, cómo dar densidad simbólica al estar o mantenernos juntos -con y sin tecnologías-, por el cómo aprendemos nuevos y viejos saberes en un mundo fragmentado, desgarrado, como el nuestro, no es una cuestión que se deban preguntar sólo los sociólogos o los filósofos, sino que nos corresponde también a los pedagogos y, diría, a la sociedad en conjunto.

En la primera parte se exponen algunas características de dicho ensamblaje tecnosocial, tanto en movimientos sociales en la red, como en grupos y actores sociales que, de manera incidental y a corto plazo, se articulan alrededor de acciones sociales y políticas concretas. Se resalta que en estos colectivos las tecnologías de la información y la comunicación han adquirido un creciente valor simbólico en los últimos años, al mismo tiempo que la política ha perdido su valor como configuradora de identidades ciudadanas. En la segunda parte, se analizan otros modos de estar y aprender juntos, a partir del trabajo de campo con cinco colectivos contraculturales de jóvenes, mujeres e indígenas en Colombia. En este apartado se destacan las cualidades de la Web $2.0 \mathrm{o}$ software social y las prácticas sociales de estos colectivos ligadas a la amistad, cooperación, intercambio, remezcla y creación de contenidos. Sin embargo, no se trata de una novedad idílica; es ambigua y está siempre amenazada por la fragilidad de los lazos sociales y la mercantilización de los conocimientos que jalona el actual capitalismo. Finalmente se plantean algunas preguntas sobre la investigación en este campo.

\section{De las nuevas configuraciones tecnosociales}

Para Bauman (2007), en el Amor Líquido, las personas extienden sus contactos a los mundos mediados tecnológicamente y son muy activos allí, porque los quieren mantener ahí, porque hay cierta resistencia, cierta incapacidad de sostener lazos afectivos (amistosos, amorosos) cara a cara. Esto sucede por una suerte de "economía afectiva" (que nos involucra mucho menos física, temporal y afectivamente) y por un sentimiento de inseguridad que la fragilidad de nuestros actuales vínculos inspira $-y$ los deseos conflictivos que ese sentimiento despierta-, provocando el impulso de estrechar los lazos, pero manteniéndolos, al mismo tiempo, flojos para poder desanudarlos. Es decir, por una parte hay cierta necesidad de común(idad) que se cuida y se mantiene, por ejemplo, a través de diferentes tecnologías (páginas sociales, blogs, etc.), pero, de otra, hay una atmósfera social que nos hace temerosos de los vínculos (especialmente de los nuevos, de los extraños) y que nos empuja a cierto aislamiento y soledad. En este sentido, parece ser que la subjetividad opera en micro-colectivos o comunidades con gramáticas de vida diseminadas que favorecen diversos modos de relación, que van desde formas de cooperación hasta formas abstrusas de aislamiento.

Sin embargo, son interesantes las diferentes facetas que nos muestran los estudios sobre las redes sociales virtuales. Uno de ellos es el trabajo de etnografía virtual que Alejandro Piscitelli realiza en Argentina sobre Facebook. En esta investigación han encontrado, por ejemplo, que existe una relación y continuidad de la comunicación on-line y off-line, una reterritorialización de las relaciones cotidianas del cara a cara en el espacio virtual, más que la creación de nuevas relaciones desterritorializadas con personas desconocidas en éste; y la estabilidad de las redes y comunidades que son definidas por los sujetos (usuarios) y no por las empresas de software (Sued, G., 2009). Rocío Gómez (2009), por otra parte, ha encontrado en jóvenes de primeros años 
de universidad en Cali, que las redes sociales como Facebook funcionan siempre articuladas a una suerte de "ecosistema tecnológico" con otras tecnologías como el móvil, el chat, el correo electrónico, es decir que estas tecnologías no funcionan aisladas ni de manera exclusiva, sino siempre en combinación con otras. En ambos estudios, sin embargo, llama la atención que si bien los jóvenes pueden tener cientos de amigos inscritos en su red social, con los que mantienen contacto y son interactivos, son amigos de la infancia, de la universidad, del barrio, familiares o sus parejas amorosas. Así, lo que estas redes y más ampliamente este ecosistema tecnológico está mostrando, es el reforzamiento de redes personales previamente existentes y no la permanente creación o ampliación de las redes sociales territoriales, como se cree.

Ahora bien, estas nuevas formas de mantener y establecer vínculos sociales a través de diferentes repertorios tecnológicos, parecen adquirir cada vez más fuerza, especialmente en las nuevas generaciones que viven un proceso paradójico de vaciamiento simbólico de la política, por una parte, y el creciente estatus simbólico de la tecnología en sus vidas, por otra. Una dimensión de lo político, a través de la activación de estas redes sociales de contactos de amigos, se ha visto, por ejemplo, en las convocatorias a marchas, manifestaciones $y$, en general, acciones en el espacio público, donde las tecnologías digitales han jugado un papel catalizador. Son prácticas políticas incidentales, que se organizan y regulan de manera compleja (en el sentido de la autoorganización) y lo que prevalece es una "política de la amistad" y de los afectos, que convoca a la acción, sobre las invitaciones que provienen del Estado o de otras organizaciones civiles, y que desaparece y se desintegra pasada la acción social. No se trata de un movimiento social que mantiene sus prácticas sociales antes, durante y después de una manifestación o movilización pública, sino de un nuevo socius, de una multitud que actúa movilizada por afectos y que conforma una unidad parcial y de corta duración, y luego se difumina nuevamente en la sociedad. Un trabajo interesante al respecto es el de Multitudes on-line, a propósito del 13-M en Madrid (Sampedro, 2005), donde se destaca la manipulación del gobierno y de los medios masivos de la información sobre el atentado de Atocha y la inesperada movilización y acción ciudadana a través de celulares y medios alternativos (Indymedia, blogs, etc.) que terminó por costarle la caída del gobierno al Partido Popular español.

Pero también los movimientos antiglobalización -o de resistencia global- han mostrado formas de articularse en red (que es anterior a las actuales tecnologías y que hoy se despliega también a través de éstas) y una capacidad de redimensionamiento de sus luchas a nivel territorial, donde la intención no es globalizar la experiencia a partir de su unificación, sino recrear formas de cooperar y actuar en diversas redes, donde cada proceso local tiene su propio lenguaje y forma de coordinación. De esta manera la comunicación y las tecnologías han empezado a tomar un lugar de importancia en los movimientos sociales que antes no tenían (Lago, Marotías, Movia, 2006; Tamayo, León, Burch, 2005). En suma, como señala Valderrama (2008), se matiza la centralidad del espacio público urbano de interacción cara a cara, llama esfera pública-, y aparece una nueva provista por la inmaterialidad de las redes electrónicas (ejemplo de ello son espacios como Facebook, Flickr, MySpace, etc.). Las prácticas sociales se constituyen en torno a valores culturales, modos de vida y construcciones de sentido (más allá de intereses de clase o sectoriales) y en oposición a modos de organización y comunicación verticales, burocráticos y rígidos; de ahí que se privilegie la adopción de un tejido organizacional y comunicativo en red, y la creciente presencia de colectivos y movimientos sociales de carácter global en la web que no obedecen directamente a regulaciones estatales.

Resaltamos aquí tres aspectos fundamentales para pensar lo común(idad) de este nuevo socius: (1) la prioridad de los lazos sociales de "amistad" y "afecto" que ofrecen un sentido de pertenencia; (2) el crear, participar, cooperar y compartir como actividades propias para ser parte de diversas redes, ya sea en esferas sociales micro o en movimientos sociales globales; (3) una materialidad y una relacionalidad que son territoriales y virtuales, y que se despliegan 
en una simultaneidad espacial. Estas tres cualidades resuenan, a su vez, con ciertas características de los actuales repertorios tecnológicos: su arquitectura en red, las plataformas y lenguajes amigables para compartir archivos de diversos tipos y crear conjuntamente, la acción a distancia, síncrona y asíncrona. Sin embargo, este encuentro tecnosocial se produce en contextos de desiguales niveles de apropiación tecnológica, y en estrecha relación con la cultura y el territorio (híbrido, físico y virtual), así como con las diversas sujeciones y posiciones de los sujetos que los conforman.

Veamos cómo estos aspectos se despliegan en unas subjetividades individuales y colectivas, $y$ en modos de vivir que, para nosotros, pujan entre formas de "política mayor" y "política menor", a partir de un trabajo de investigación realizado con diferentes colectivos contraculturales en Colombia ${ }^{4}$. Dicho estudio, de corte cualitativo, nos permitió indagar profundamente en esa subjetividad que experimentan, de manera compleja, viejos y nuevos referentes identitarios, una inconformidad con el mundo que vivimos, así como la emergencia de prácticas sociales y educativas, catalizadas a través de tecnologías de la información y la comunicación que, de diversos modos, hacen resistencia a los modelos hegemónicos y homogenizantes del mercado.

\section{De otros modos de estar y aprender juntos}

Dadas las restricciones de espacio para presentar detalladamente cada colectivo, intentaremos, a través de unas imágenes, traerlos a nuestro texto, sin embargo, advertimos que son representaciones y,

4 Nos referimos aquí a nuestra investigación Cultura política, ciudad y ciberciudadanías, estudio realizado entre la Universidad Pedagógica Nacional y la Universidad del Valle, con el apoyo de Colciencias (contrato COLUPN, No. 201306), entre 2007 y 2009. En esta investigación participaron personas vinculadas a los grupos de investigación Educación y Cultura Política de la Universidad Pedagógica Nacional (Luz Marina Suaza, Andrés Fonseca, Vladimir Olaya, Lina Ramírez, Yeimy Useche, Yeimy Cárdenas y Rocío Rueda 0.) y del grupo de investigación de Educación Popular de la Universidad del Valle (Rocío del Socorro Gómez, Julián González, Armando Henao, Viviám Unás y Diana Giraldo). Del Colectivo de Comunicaciones NASA-ACIN fueron coinvestigadores Vilma Almendra y Gustavo Ulcué. como tales, reducciones de la riqueza y diversidad que estos sujetos colectivos encarnan ${ }^{5}$.

\section{Nativos del territorio, pero conectados globalmente}

El colectivo de Comunicaciones NASA-ACIN ${ }^{6}$, desde su proyecto político por la vida, ha incorporado, hecho propias las tecnologías de la información y la comunicación, como parte de las demandas de trabajo de su organización, para enriquecer sus diversas prácticas sociales, culturales y políticas a nivel nacional e internacional. Para ello han creado la "Chiva net", para llegar hasta aquellos lugares donde no hay conexión a la red, llevando en la Chiva los diskettes, hasta su plataforma en Internet, donde se presenta (contra) información sobre las diferentes acciones de la comunidad Nasa y del movimiento indígena en general a nivel global. Su página tiene textos en lengua nasa, en castellano, en inglés, francés y alemán. Los jóvenes indígenas que conforman este colectivo publican artículos de carácter político y cultural sobre la situación actual de la comunidad Nasa, pero también sobre otros hechos del país que tienen que ver con las injusticias, desigualdades y atropellos a los derechos humanos; graban videos sobre la Minga, sobre sus movilizaciones, que luego suben a través de YouTube; coordinan acciones en tiempo real a través de correo electrónico y de celulares, y actualizan su página web. Han aprendido a utilizar estas tecnologías, primero a través de algún curso en un telecentro, y luego, a través de la exploración y el autodidactismo. No son nativos digitales, pero tienen una voluntad de conocimiento que otorga a las tecnologías una potencialidad política y pedagógica vinculada a procesos de emancipación y autonomía social, como sucede con otros movimientos sociales en la red. Este colectivo se mantiene en medio de tensiones políticas -en el interior del movimiento indígena y sus formas de organización-, amenazas de poderes estatales y paraestatales, así como luchas culturales, étnicas y de género.

5 Se retoman aquí fragmentos de nuestro artículo: “Cibercultura y educación: mundos que habitamos, mundos que creamos". En: Magazín Aula Urbana, No. 74, IDEP, Bogotá, 2009, pp. 16-17.

6 Ver: http://www.nasaacin.net 


\section{Movimiento de mujeres, mujeres en movimiento}

La Corporación Vamos Mujer, así como otros colectivos de mujeres, sabían qué son las redes sociales mucho antes de que aparecieran las que hoy, a través de Internet, están tan de moda. Ellas, feministas, desde los años 70 han estado vinculadas al movimiento social de mujeres que busca su reconocimiento y visibilización, una vida digna, sin violencia y pacifista. Su lucha es contra el patriarcado y la lógica binaria dual, así como contra las desigualdades e iniquidades en Colombia. Las tecnologías de la información llegan a la Corporación, inicialmente para apoyar labores administrativas, pero con el tiempo, al hacerlas propias, su política se tecnologiza, al ser aquéllas estratégicas para la visibilidad y la coordinación de acciones sociales, políticas y culturales glocales. Son mujeres inmigrantes digitales; el territorio, el encuentro presencial off-line sigue siendo fundamental, y sus prácticas sociales y educativas se sustentan en la solidaridad, la afectividad, la cooperación, la participación, el intercambio de saberes y el empoderamiento de las mujeres en condiciones de desigualdad e injusticia social. De igual manera que en la comunidad Nasa, es a un proyecto político al que se integran las tecnologías y, en consecuencia, es éste el que les otorga un lugar y sentido en sus diferentes prácticas sociales. Sin embargo, la incorporación de éstas es un proceso lento. Para este colectivo las acciones más significativas ocurren en las redes sociales locales (no digitales) y en la reconfiguración y búsqueda de nuevos horizontes políticos más localizados. Así, la página web, por ejemplo, surge como una necesidad de expansión política de la organización, pero dista mucho de ser un proyecto colectivo que les concierna a todas. De hecho, la gran actividad y multiplicidad de trabajo y acciones en redes que tienen en el lugar, en el territorio, contrasta con la relativa lentitud con la que se mueve y actualiza la página web. Asimismo, contrasta que las nuevas generaciones de mujeres vinculadas a este colectivo no están interesadas en el feminismo, y aportan, al contrario, su entusiasmo por realizar acciones a través del ciberespacio.

7 Ver: http://www.vamosmujer.org.co

\section{La Cápsula, el Niuton, Mefisto: remix y creación colectiva $^{8}$}

Estos jóvenes, nativos digitales, urbanos, han apropiado el carácter contracultural de las tecnologías informáticas (la contracara académica y hippie del origen militar de las mismas), por lo tanto apuestan por una cultura de la información para la creación colectiva, de libre circulación, del creative commons y del copy left ${ }^{9}$. Son, ante todo, jóvenes insatisfechos con las formas tradicionales de política y cultura; producen con diferentes medios y tecnologías, realizan intervención urbana, participan en talleres abiertos y fiestas del software libre en comunidades marginales o encuentros internacionales; también apoyan a otros movimientos, como fue la Minga indígena. Sus prácticas profesionales y sociales crean formas de educación expandida, en las que se mezclan y combinan saberes sobre diseño, software y programación, arte, cultura y política. A diferencia de los yuppies informáticos de las empresas multinacionales, estos jóvenes apuestan por la creación tecnocultural que parte de un nosotros y un común, que se construye desde afectos y redes de amistad y solidaridad glocales, aunque parciales y frágiles, y no sin contradicciones en relaciones de poder y género, y en las maneras de subsistencia en las esferas de producción con bienes informacionales. Para ellos, la tecnología se politiza y poetiza desde la creación de obras que mezclan arte, tecnología, ciencia y cultura. Ellos, porque son mayoritariamente hombres, viven la tensión de trabajar para vivir y tener con qué dedi-

8 Ver: http://www.elniuton.com; www.lacapsula.com; www.mefisto. org

9 Copyleftes una institución legal creada por los movimientos sociales para combatir la llamada propiedad intelectual. El copy left es una desterritorialización del copyright, que se reterritorializa bajo la forma del reconocimiento legal, solamente para liberar el derecho de copia y de reproducción, es decir, para ampliar los espacios en los que se pueden expresar las singularidades y la multiplicidad intertextual con las que se crea cualquier producto intelectual. Mientras que la institución representativa de la propiedad intelectual captura y fragmenta el común productivo, reduciendo la elaboración de un producto a lo uno (el autor), el copy left crea una institucionalidad abierta a la potencia constituyente de las multiplicidades ( $c f$. Fernández de la Rota, 2008). La plataforma $c c$ mixter (www.ccmixter.org) permite remezclar la música de artistas, hacerle variaciones, compartirla, crea un escenario propicio de nuevas prácticas sociales. 
carse a hacer lo que les apasiona: crear, compartir y distribuir. Por ello, a pesar de sus apuestas contraculturales y libertarias, muchos deben tomar trabajos como programadores o diseñadores en empresas, en el modelo más salvaje y competitivo del actual capitalismo informacional. Sin embargo, parecen adaptarse camaleónicamente a uno y otro ambiente de producción informática.

\section{Chicas Linux, mujeres en el software libre ${ }^{10}$}

Estas jóvenes son nativas digitales, de clase media y urbana. Están inconformes con ciertos comportamientos masculinos agresivos, individualistas y competitivos en los ambientes de creación de software, pero no son feministas. Sin embargo, valores considerados como femeninos como la solidaridad, la afectividad, el cuidado del otro, son fundamentales en su quehacer como programadoras del software libre. Asimismo, la cooperación, el intercambio de saberes y el empoderamiento de las mujeres en el uso de este software, son su apuesta política contra la hegemonía de los modelos propietarios de los bienes informacionales. El intercambio de saberes se produce principalmente en entornos virtuales, en listas y foros, pero existen también encuentros presenciales y talleres de autoformación, en los que se apoyan mutuamente en la resolución de problemas técnicos y logísticos para sus trabajos con comunidades marginales. Viven la paradoja de los tiempos acelerados y la dificultad para llevar simultáneamente su vida personal y familiar con el mundo de la programación -que exige más dedicación- y donde dinámicas masculinas, individualistas y competitivas, a pesar de un discurso libertario, predominan.

En un intento de síntesis de estas imágenes, diremos que las nuevas formas de práctica social y de común(idad) sociotécnica se despliegan en un espacio de redes, físicas e inmateriales, en diversas esferas micro y macro que se superponen. Se crean modos de vida que van y vienen en ambientes on $y$ off-line, llevando dimensiones de un espacio al otro, y donde se destaca una capacidad para asumir y ac-

10 Ver: http://www.chicaslinux.org tuar sobre cuestiones locales o de carácter global. En algunos casos hay una configuración sociotécnica, donde la prioridad de un proyecto político y los discursos históricamente construidos y transformados, son los que definen una acción y configuran, en buena medida, su identidad, tal como sucede con los movimientos sociales, indígenas y de mujeres; en otros casos, provienen de búsquedas contraculturales en el arte y la tecnología, pero también de la coyuntura, del encuentro de subjetividades inconformes y creativas, desde donde le otorgan un lugar a las tecnologías y, con ellas, a los sujetos. Todo esto ocurre gracias a prácticas de autoorganización y autodeterminación, que a veces se basan en modelos jerárquicos, y otras, en formas inesperadas de articulación de acciones no previstas y horizontales. Esto se produce en medio de unas historias, sus lugares, y las diferentes maneras y fuerzas de poder con las que los sujetos sociales deben lidiar, es decir, con las diferentes opresiones que, como sujetos individuales y colectivos, nos habitan. Así, por ejemplo, algunas mujeres indígenas que usan activamente los nuevos repertorios tecnológicos para participar en luchas globales, lo hacen en medio de relaciones de subordinación en su esfera privada y comunitaria. $\mathrm{O}$ jóvenes artistas, productores de obras de netart o de música electrónica en redes globales de cooperación y de software libre, que paralelamente se contratan en una empresa como desarrolladores de software -en el modelo más competitivo del mercado-,para sobrevivir y subvencionar sus obras libres, que luego donarán a su comunidad o red de artistas contraculturales. En algunos casos, estos colectivos apoyan acciones ciudadanas organizadas por movimientos sociales, como la Minga Comunitaria, pero son articulaciones parciales que pueden repetirse en el tiempo, sin tener una identificación con las luchas reivindicatorias étnicas. Eso se lo dejan al movimiento indígena.

Pero mantengamos en mente estas imágenes de los colectivos antes presentados y veamos cómo, en ese entretejido de nuevas formas de acción social y política, también se encuentran unas prácticas educativas que, a nuestro modo de ver, tensionan las instituidas, y donde en medio de subjetividades 
contingentes, hay en común una apuesta por la acción -individual y colectiva- que se opone a los modelos hegemónicos y uniformizantes de la cultura. El aprendizaje se produce como un proceso de participación en varias prácticas culturales, donde prevalecen la colaboración y el compartir y mezclar saberes, y donde la autoridad es coasumida y está en permanente tensión entre nosotros; donde la cognición y el conocimiento están distribuidos en los individuos y sus entornos, y donde el aprendizaje es un proceso autorregulado, situado -offy on-line- en relaciones y redes de interacción.

\section{Aprender juntos: tradiciones y contemporaneidades}

Hoy, trabajando desde nullun y compartiendo enlaces con matiasjajaja, me mostró la integración de Twitter con Livestream en Twitcam y nos pusimos a jugar con él. Dejó el video (que queda archivado) y los comentarios de los amigos al preguntarles: ¿cómo les parecía el Mashup y para qué podrían usarlo ${ }^{11}$

iamrafa: yo lo usaría para cubrir eventos en vivo... periodismo ciudadano.

carloscaicedo: Yo soy arcaico, prefiero gtalk .

carloscaicedo: @ledymarmalade: Tenés razón... es muy jarto que el chat se vaya pa' tuiter... cuando parchamos?

elniuton: es mas foro... no pa hacer visita martin.

leidymarmalade: de pronto para los tales debates que quieren hacer.

leidymarmalade: no me gusta que bote el update a twitter.

Blog La Cápsula (por datalove): agosto 27 de 2009

En estos diferentes colectivos encontramos una multiplicidad de prácticas sociales, modalidades híbridas que comparten tradición y contemporaneidad. Así, por una parte, en el caso de sujetos

11 La siguiente conversación está transcrita literalmente del Blog de la referencia. Los comentarios están ordenados cronológicamente, desde el más reciente (primero) hasta el más antiguo (último). sociales del tipo movimiento social -como para esta investigación fueron ACIN o la Corporación Vamos Mujer-, la dimensión educativa surge de demandas concretas (no siempre previsibles) que el colectivo -y su proyecto- le hacen a sus participantes; son esas demandas las que impulsan a las personas a aprender conocimientos nuevos (como elaborar proyectos, realizar páginas web, listas de correos, etc.), a potenciar saberes que ya se poseen, a cualificar las capacidades expresivas y de argumentación política en programas de educación formal (pregrados, maestrías, especializaciones, etc.) o a adentrarse en el aprendizaje con pares, o con generaciones más jóvenes, para producir obras que involucran nuevas tecnologías de la información y la comunicación. En efecto, los usos de las tecnologías y las prácticas educativas responden siempre a demandas de trabajo que vienen dadas por las búsquedas políticas de la organización (luchas de reconocimiento de derechos, denuncias, visibilización, sensibilización moral, llamado a movilizaciones en el espacio público de la ciudad, etc.). Pero al mismo tiempo, y de manera cotidiana, se ha instalado el autoaprendizaje y el aprender entre pares, como una práctica común y sostenida en estos colectivos, lo que a su vez permite que la autoridad se invierta o se descuide para flexibilizar las relaciones y las tomas de decisiones, como sucede de manera más evidente en el caso del colectivo de comunicaciones NASA-ACIN, donde los mayores han aceptado aprender y negociar con los saberes de las generaciones jóvenes del Tejido de Comunicaciones. Así, vemos una subjetividad que se configura desde modelos educativos convencionales, pero también desde una intensa labor de autoaprendizaje con otros.

Por otra parte, para sujetos sociales como Mefistófeles, La Cápusla, el Niuton, Chicas Linux, la dimensión educativa está ligada a una práctica investigativa cultural, artística y tecnológica, caracterizada por la creación respectiva de obras en diversos lenguajes (desde el graffiti urbano hasta programas de computador), por el uso más intensivo de variados repertorios tecnológicos, por una inteligencia colectiva basada en el compartir, en el goce del descubrimiento y la exploración. Lo educativo, 
entonces, surge como una comunicación espontánea de colaboración, de intercambio y de "donación"; la autoridad está distribuida en diferentes nodos de la red o microesferas que conforman estos colectivos. Las tecnologías son ambientes de creación, y para ello se experimentan, a veces de manera paradójica, todas sus formas -las comerciales y las que están del lado del software libre y del creative commons- para lograr sus objetivos. El mundo de la tecnología hace parte de sus contenidos, del mundo común del que se habla y desde el que se discute sobre la contemporaneidad (como son, por ejemplo, muchos de los artículos de las revistas del Niuton o de Mefisto), pero es además su modo de vida, en formas de organización distribuida que facilita la creación del común que los une como singularidad, como nodo de la red y, al mismo tiempo, con otros nodos. El uso de las nuevas tecnologías de la información se ha convertido en una suerte de laboratorio social interesante para probar formas de organización política en el interior de estos colectivos, así como la creación colaborativa y distribución de obras, en las que cada quien comparte lo que sabe, y que como hemos dicho, pueden ser desde un programa de software libre, una página web, un graffiti urbano, electrónico, hasta una revista digital.

Lo que constituye un común es, a veces, un discurso construido históricamente con el que los colectivos se identifican (feminismo, ecologismo, anticapitalismo, contracultura, etc.), en otras ocasiones, un proyecto político, artístico, tecnológico o cultural específico y que tiene una duración en el tiempo; y, en otras, coyunturas, contactos con "diferentes" sujetos con los que se construye empatía, intersubjetividad que aporta y enriquece las prácticas sociales. A veces, es una mezcla de todas estas posibles fuentes de comunidad. Para ello, los colectivos acuden a la exploración de una racionalidad estético-expresiva, donde vemos que se están produciendo prácticas educativas expandidas interesantes: por una parte, prevalece el aprendizaje con pares o con personas más jóvenes en un ambiente de amistad y fraternidad, de confianza en los saberes de los otros y en clara crítica a los modelos disciplinares y profesionales -aislados y estancos- de la academia; esta es una dimensión epistemológica nada despreciable, como plantea Ana María Fernández (2009), pues cuestiona la figura del "único autor" y apunta a la construcción de saberes más allá de los dominios de objetos disciplinarios. Por otra parte, en todos los casos se elaboran obras colectivas -aunque tengan momentos de trabajo individual- que integran diversos lenguajes y sus respectivas materialidades, desde boletines escritos, collages, graffitis, performances, emisiones de radio, hasta páginas web y blogs. También diremos que se acude al uso de la ironía, del humor, de metáforas que buscan el juego con otras formas de comunicación, educación y expresión política, y que estallan los lenguajes acartonados de la política y la academia. Aquí vemos una subjetividad, una multitud que se resiste a modelos dominantes (educativos, culturales, políticos, sociales, tecnológicos) e insiste en su expresión y libertad, en su autogobierno y autodeterminación.

Las prácticas educativas tienen entonces un tiempo expandido: se aprende todo el tiempo y a lo largo de la vida, y se acude a un lenguaje que instala un aprendizaje social, donde se incita a tener voz propia, que se traduce en algunos colectivos como el “do it yourself”. Esta expresión, sin embargo, tiene una carga simbólica paradójica, porque, por una parte, tiene la fuerza del desilenciamiento o la "toma de la palabra" donde las tecnologías, a partir del trabajo individual, devienen lenguajes cooperativos, horizontales y múltiples, pero por otro lado, también representa competitividad, eficientismo e individualidad, actitudes que requiere el actual mundo productivo y de los programadores. De hecho, a través de este "do it yourself" también se ejercen prácticas de exclusión y desigualdad hacia otros con menos conocimiento en el campo informático, hacia mujeres o simplemente hacia quienes no son "capaces de hablar su lenguaje". Sin embargo, queremos resaltar aquí la potencia de la toma de palabra que opera como un reencantamiento de las prácticas sociales locales-globales e inmediatas-diferidas, toda una dimensión estético expresiva que puede conducir a novedosas formas de creatividad social. 
Nosotros como colectivo lanzamos una propuesta que quiere romper con los tipos de lectura citadinos, acogiendo elementos electrónicos (leds, sensores de movimiento, entre otros) y gráficos que permitan una nueva experiencia entre el transeúnte y nuestro mensaje. De esta forma queremos acercarnos a nuestra ciudad de manera individual para construirla de manera colectiva; hacer de esta, de sus monumentos y del concreto una página más, una página abierta que espera ser escrita y leída de manera diferente.

Página - El Niuton

Los nuevos repertorios tecnológicos, especialmente aquellos derivados del desarrollo de la Web 2.0 o red social, son tecnologías más cercanas o propicias para las prácticas sociales que estos colectivos realizan, pues a diferencia de otras tecnologías que les precedieron -que no permitían la descentralización de la circulación lingüística, perceptiva y cognitiva-, éstas se acoplan a la descentralización de los medios de expresión, con otros regímenes de signos -hipermediales e hipertextuales- que son capaces de integrar medios y que son "potencialmente más favorables" tanto para el plurilingüismo y las plurinteligencias (Lazzarato, 2006), como para el trabajo colectivo, la cooperación y la producción y libre circulación de bienes comunes ${ }^{12}$, en donde vemos fuertes implicaciones educativas. Diremos pues que esta novedad social de la que hablamos se materializa en la expresividad de las multiplicidades, precisamente en el desbordamiento de la institución representativa (sujeto, Estado, soberano, educación, etc.) y donde el sujeto de la experiencia, siguiendo a Larrosa (2000), está dispuesto a transformarse en una dirección desconocida. Un ejemplo muy interesante es todo el ejercicio de aprendizaje de los jóvenes de la comunidad indígena NASA-ACIN, para quienes su trabajo en el Tejido de Comunicaciones, les ha transformado de una manera que no imaginaban. Ellos han "caminado la palabra", pero al mismo

12 Nos referimos aquí, principalmente, a las tecnologías que permiten una mayor personalización y comunicación en Internet a través de la participación, conectividad, colaboración y compartir conocimientos e ideas. Ejemplo de ello son los blogs (foto/videoblogs), wikis, redes sociales y las utilidades $\mathrm{P} 2 \mathrm{P}$, entre otras. tiempo se han transformado, son ciberactivistas, con todo lo positivo y negativo que esto les ha traído a sus vidas. De ahí que el aprendizaje requiera ser permanente, y que el aprendiz sea un co-productor, más que un consumidor de información. El modelo de lecto-autor de Barthes (1974) y Eco (1974), y las formas de autodirección y autogobierno de comunidades on-line y de redes de actores, claman por sujetos participantes, productores. Los individuos hacen parte de diversos comunes, combinan la toma de decisiones y el movimiento, la creación de consensos locales y una capacidad afectiva que los une, como individuos, a un todo, una multitud, colectivo o red, de manera situada y parcial.

\section{La remezcla colaborativa, compartir y la inteligencia colectiva}

Las chicas que hayan trabajado en IT (y las que no también) están cordialmente invitadas a participar de el proyecto WoMoz: Women And Mozilla. Sólo el $2 \%$ de las personas que trabajan activamente en proyectos de desarrollo de software libre son mujeres, por eso nació esta iniciativa de atraer más mujeres al software libre a través de este proyecto. Entonces, chicas, ¿qué esperan para unirse al ejército del software libre?

Enviado por Monyu el 09/10/2009 - 6:11pm- Página ChicasLinux

En estos colectivos las prácticas educativas, como hemos señalado, están basadas en el aprendizaje colaborativo, a veces intergeneracional, entre pares, con objetos comunes -aunque multidisciplinaresde conocimiento y subjetividades dispuestas a la investigación. Las relaciones de autoridad, jerarquía y conocimiento se tensionan y se aprende un nuevo lenguaje en medio de prácticas de fraternidad y amistad, donde se comparte lo que se sabe y se mezcla con los saberes de otros. La educación se expande, se sale de los "lugares ciertos" y se convierte en una práctica social y colectiva. Asimismo, las características de la Web 2.0 se acoplan a dichas prácticas sociales porque estas tecnologías ofrecen entornos para una interacción conversacional, apoyan una retroalimentación social y las redes y 
relaciones entre los individuos. Hay que ver trabajar a algunos de estos jóvenes que mantienen diferentes ventanas de chat abiertas mientras producen una obra, se comunican vía escrita (pero también con videoconferencia), se intercambian archivos síncrona y asíncronamente. Estos son ambientes naturales de trabajo y de comunicación. Por ello, la estructura y contenidos de estas tecnologías surgen de procesos intensivos de comunicación, no como un producto de un diseño previamente definido, sino como un rasgo emergente de la interacción, participación y autoorganización. No obstante, también debemos resaltar que en colectivos como ACIN o la Corporación Vamos Mujer, que tienen una trayectoria histórica mucho más larga, la presencia de otros medios como la radio o los boletines impresos sigue siendo importante, y lo es, por cierto, por otra razón: estos sujetos sociales están comprometidos con poblaciones que tienen escasez de recursos económicos y no tienen necesariamente acceso a la red o al computador. Ellos tienen que buscar todas las modalidades posibles para mantener el contacto con esa población a la que dirigen sus acciones prioritarias -y que no están muchas veces en las ciudades- $y$, al mismo tiempo, con los otros actores sociales globales de los que hacen parte. Así, conviven tecnologías de la escritura del papel y de los bytes, con sus respectivas prácticas educativas.

El hecho cotidiano de aprender entre pares, colaborar, remezclar y combinar, consideramos que da cuenta de una inteligencia colectiva, que entendemos, de acuerdo con Sloterdijk (2008, p. 8 ), una "inteligencia que es como el lenguaje y las emociones, no es la inteligencia de un sujeto, sino un entorno o un sistema de resonancia" donde sujetos creadores, en progress, son capaces de estar en contacto con muchos otros, trabajando de manera liberada y en espacios-tiempos diferentes, con una conciencia planetaria. Tanto los jóvenes del colectivo NASA-ACIN, como los del Niuton, trabajan simultáneamente con actores sociales de otros lugares del mundo. Si se observan las páginas de uno y otro colectivo, se puede notar la interacción que tienen con otras redes para asuntos de carácter planetario, sea el movimiento por la Madre Tierra o por las tecnologías low tech; en cualquier caso, a estas subjetividades les cabe el mundo en sus pensamientos, en sus acciones. De aquí que en términos educativos nos interesa destacar esa subjetividad con todo y sus marcas -rebelde, que no se acomoda a estándares-, pero que también tiene rasgos de modelos tradicionales educativos y culturales, que es capaz de aprender de y con otros, en una suerte de "remezcla colaborativa" (McLoughlin, 2007), en un proceso de transformación en el que la información y los medios están organizados, dispuestos y compartidos para ser (re)combinados y construir nuevas formas, conceptos, ideas, diseños. En efecto encontramos aquí, como lo plantea Fonseca (2009), las potencias de la mezcla, del mestizaje, la combinación, el collage, las intersecciones e interfaces, que pueden llevar a formas de conocimiento nómadas y a formas de aprendizaje colaborativo. De ahí que investigadores ciberculturales hablen de subjetividad de código abierto o $d j$, esa subjetividad que crea mientras va comprendiendo, mientras avanza, amplía su percepción de modos de vida.

\section{Contenidos abiertos y una política de la amistad o de la amistad como política}

En nuestro caso, asumimos una interpretación muy ampliada de la política, que se vincula a la crítica cotidiana, a la trasgresión de principios y costumbres, al rechazo al consumismo como única forma de desarrollo personal, al compromiso de pensar y mirar hacia el futuro.

No está de más recordarles que esta es una publicación que requiere de su colaboración para alcanzar nuevos públicos (rótela, difúndala, reprodúzcala libremente) y también para la continuación de su proceso editorial que seguirá explorando nuevos temas, para lo cual los invitamos a pensar en la contracultura y la transgresión cultural en las fronteras de la legalidad y la legitimidad. De esta mezcla, surgirá la base para nuestro tercer número.

Editorial Revista Mefistófeles

En la mayoría de estos colectivos (especialmente aquellos vinculados con tecnología, arte y cultura) 
la relación con las tecnologías está atravesada por una apuesta política en relación con la creación de contenidos abiertos, de acceso gratuito y que invitan a seguir creando - por oposición a prácticas propietarias de los bienes comunes-, a la experimentación y a la difusión del conocimiento (a través de licenciamientos tipo Creative Commons, o Copy Left). Este asunto, para nosotros, moviliza no sólo alternativas de coexistencia, sino que de alguna manera está promoviendo un descentramiento de las figuras modernas de disciplinamiento, alfabetización y formación. Poner en entredicho, a través de unas formas de ser y de trabajar, de pensar y de sentir, un conjunto de dinámicas sociales establecidas como las de autoría, la recepción o consumo, la propiedad intelectual, el trabajo individual y competitivo, es un ejercicio ciudadano, formativo y político que opera no sólo confrontando los grandes relatos, sino estremeciendo los marcos existenciales de la subjetividad.

El aprendizaje de pares, las redes de amistad, la creación de contenidos abiertos, el intercambio de saberes y el uso de los repertorios tecnológicos de modos expresivos, hace que cada integrante comparezca como un nodo que se articula con una problemática consensuada parcialmente y con unos saberes que ponen a prueba su capacidad de comprensión y de imaginación, configurándose así escenarios de experimentación social, laboratorios híbridos de creación colectiva. Es decir, no es un aprendizaje de pares, como el que se ve muchas veces en la escuela, en el que se sientan dos o tres en un computador a responder las preguntas del profesor o del software didáctico. Se trata de producir colectivamente contenidos (aunque ello implique fases de cierta individualidad), crear nuevos objetos, no sólo consumir información. El conocimiento, entonces, deviene emancipación (que no regulación) pues, como nos ha dicho Boaventura de Sousa (2003), la solidaridad es el conocimiento obtenido en el proceso, siempre inacabado, de volvernos más capaces de reciprocidad a través de la construcción y del reconocimiento de la intersubjetividad.

De esta manera, la amistad, como señala Agamben (2005) tiene un rango ontológico y, al mismo tiempo, político. La dimensión estético-expresiva del ser está, de hecho, siempre repartida y compartida, y la amistad nombra este compartir con afecto, que aquí se disemina en diferentes espacios y entornos tecnológicos y en acciones de creación colectiva. Por ello, para estos sujetos sociales, más que una política de la amistad, como diría Derrida, lo que experimentan es la amistad como política. Política que reconoce el don de la gratuidad de estar, entre algunos, entre muchos, del compartir "bienes comunes". Esta política se nos presenta a contramano de esa feroz insistencia de las lógicas capitalistas donde, por una parte, cada vez más se tiende a restringir el acceso libre a las nuevas condiciones materiales de la vida colectiva a través de nuevas normas, protocolos de uso y regulación en el acceso a bienes informacionales. Y, por otra, diseñadores, programadores $\mathrm{y}$ artistas han de trabajar en red, pero para acceder a información, para que sea útil y tenga valor, no para compartirla. Práctica profesional que a su vez va acompañada de la producción de soledades que separan, aíslan a cada quien de sus potencias (Fernández, 2009), y con la cual se las tienen que ver a diario los nuevos trabajadores inmateriales, como son, en su diversidad, los sujetos de los colectivos que aquí presentamos.

\section{De la vitalidad del socius y las posibles heterotopías}

Necesitamos ritualidades para poder mantenernos en actuación de resistencia, si no tenemos ritualidad colectiva, la resistencia será imposible sostenerla para responder ante una avalancha de cosas que cada vez son más complejas, que exigen competencia y te ponen a rivalizar con el mundo.

Luz Estella Ospina Murillo - Corporación Vamos Mujer

Lo que debe ser, todavía no existe más que en nuestro compromiso, en la memoria de todo lo que vive y en lo que tenemos que inventarnos, sembrar y proteger para abrir el camino.

Mandato Indígena y Popular - Comunidad NASA-ACIN

Se trata de una nueva espacialidad difícil de cartografiar, pues está hecha de cuerpos que habitan lugares, que tienen marcas culturales, de género, clase social, de raza, profesión, etc. Estos casos de nuevas formas 
de socialidad, de multitud que hemos presentado aquí, y muchos otros que palpitan en diferentes rincones del mundo, como las experiencias de pedagogías feministas decoloniales que ha encontrado en su trabajo doctoral Tania Pérez Bustos (2010) en Colombia e India, o las que señala Oscar Guardiola (2009) refiriéndose a las prácticas de desaprendizaje $y$ de reexistencia (que se producen en los lugares de cuidado, o de confrontación o solución de conflictos), distan mucho de conformar un todo coherente, pero pueden ser -y son - cuerpos funcionales de conocimiento, valiosos para inventarnos mejores y más justas formas políticas en la cotidianidad. Éstas nos invitan a que desaprendemos formas sociales, políticas, educativas, que en el pasado fueron únicas, coloniales, homogenizadoras.

Pero al mismo tiempo, nos recuerdan que, a pesar de las apuestas libertarias, de rebeldía e inconformismo con lo establecido, en estos colectivos hay internamente asuntos vinculados con las relaciones de poder, de género, de raza, de clase social, profesión, que aparecen de forma ambigua, que se invisibilizan y que parecieran convivir no siempre de manera armónica en este contexto social, como es el caso de las prácticas marcadamente masculinas y competitivas en ciertos colectivos del software libre, o las relaciones jerárquicas en colectivos contraculturales de mujeres que se oponen a modelos políticos autoritarios. En efecto, vemos una condición compleja, de hibridez, de contemporaneidad no contemporánea de tiempos culturales y de vulnerabilidad, que nos exige un estado de alerta con la teoría a la que acudimos y con nuestros propios acercamientos académicos al mundo cibercultural -por más teoría postmoderna amiga de las diferencias y de la multiplicidad a la que acudamos-. Se requieren estudios que logren dar cuenta con mayor profundidad de esas sutiles convivencias de tiempos y espacios culturales y políticos en los mismos sujetos individuales y colectivos, de las grietas por donde en medio de la lucha por lo múltiple y la diferencia, se cuela la homogenización rampante y la desigualdad. De esas maneras en que simultáneamente se rescatan dimensiones de la subjetividad que fueron excluidas del pensamiento moderno (como la afectividad, el deseo) y donde se mantienen intactas las exclusiones de género, raza, de clase social y de región, como de hecho, diremos, es notorio en estos colectivos que son mayoritariamente urbanos y de clase media.

Asimismo, las tecnologías no son suficientes ni determinantes per se, en cuanto a las opciones sociales y educativas, y a los agenciamientos culturales, porque son las dimensiones colectivas de uso, las que constituyen escenarios de comunicación, espacios para la diseminación de lo sensible y lugares donde se trazan diagramas de la creatividad social y del deseo. Por ello hemos querido ver la potencia que tienen los colectivos que seleccionamos, pues creemos que la amistad como política, el aprendizaje de pares, el compartir, el donar, la expresión y la circulación libre de bienes, nos ponen ante nuevas formas de entender la formación de la subjetividad y una educación expandida desde prácticas sociales que aún no es fácil encuadrar. Es en esas prácticas que las tecnologías y sus ambientes para la participación y la colaboración -como la red social o Web $2.0-$, resultan interesantes para pensarlos desde su potencia política.

Para concluir, volvamos a la instancia de lo común, pero también a su enigma o su dificultad, a su carácter no dado, no disponible y en ese sentido lo "menos común del mundo". Si somos, como diría Blanchot (2002), la "comunidad de los que no tienen comunidad”, entonces ¿cómo se construye lo común?, ¿cómo el comunicar la experiencia y la fuerza del deseo nos constituye?, ¿qué es lo que nos hace nosotros, separándonos y acercándonos?, ¿ cómo es que ese sujeto social (multitud, red social, colectivo, etc.) se autoorganiza y gobierna sin "contrato social" en esa fundamental relacionalidad o conectividad de cuerpos, afectos y subjetividades? En ese sentido, consideramos que tenemos el reto de seguir cuestionando nuestros propios marcos interpretativos, pues el mismo concepto de red que en principio nos parece tan apropiado, remite a una representación espacial de nodos y relaciones un tanto estática y estable que da un mayor énfasis a los nodos, como, de hecho, lo hemos mostrado aquí. Sin embargo, lo que nos está señalando este socius, esta multitud, es 
su imprevisibilidad, es que estas redes, sobre todo, se mueven, se relacionan, interactúan y se autotransforman, así que quizás debamos complementar o acudir a otras metáforas y estudios para comprender su movimiento y dinámica temporal, así como su expresión en una acción política distribuida, horizontal y heterogénea ${ }^{13}$. En los cinco colectivos contraculturales que consideramos en este estudio, si bien hay una categoría discursiva que les da una identidad (mujeres, jóvenes, indígenas), existen diferencias internas, diversas posiciones de sujeto y maneras parciales de articularse a los colectivos en los que participan y a las prácticas sociales de resistencia al poder, donde están en tensión también aspiraciones y sueños individuales.

En cualquier caso, se trataría de metáforas que den cuenta de la complejidad de esta vitalidad tecnosocial y de la convivencia de formas tradicionales y novedosas de organización social y política, así como de nuevas y tradicionales formas y prácticas educativas. Otro desafío que tenemos, es intentar comprender mejor cómo se produce esa combinación táctica entre conectividad y conformación de

13 En este caso, quizás los estudios contemporáneos sobre la “inteligencia de los enjambres" que combinan una tecnociencia de los sistemas vivientes, etología, biología, elementos de la física del caos, puedan darnos pistas al respecto. Ver Thacker, 2004.

\section{Bibliografía}

Agamben, G. (2005). La amistad. En La Nación, edición del 25 de septiembre. Buenos Aires.

Barthes, R. (1974). El proceso de la escritura. Argentina: Ediciones Caldén.

Bauman, Z. (2002). Modernidad Líquida. Buenos Aires: Editorial Fondo de Cultura Económica.

(2007). Amor Líquido. Buenos Aires: Editorial Fondo de Cultura Económica.

Bataille, G. (1986). La experiencia interior. Barcelona: Taurus.

Beck, U. (2000). Un nuevo mundo feliz. La precariedad del trabajo en la era de la globalización. Barcelona: Paidós. común (idad, red, multitud) y cómo las formas de control y diversas dinámicas de poder (co)existen, aún en estas formas alternativas de redes y multitudes.

Frente a las monstruosidades del pensamiento único, y de las prácticas y teorías que nos mutilan, separándonos, y nos llevan a creer que cada vez podemos hacer menos, requerimos, como dice Boaventura de Sousa (2003), una esperanza que no reside en un principio absoluto que aboga por un futuro en general, sino antes, en la posibilidad de crear campos de experimentación social, heterotopías, de espacialidad en red y de acciones simultáneas, donde sea posible resistir a los colonialismos aun presentes en la contemporaneidad y que van construyendo, un poco por todas partes, alternativas locales y globales que vuelvan posible una vida más digna, más solidaria, más bella, más alegre. Pero al mismo tiempo, como hemos señalado aquí, es necesario estar alertas a las euforias por esta novedad social, que rápidamente tienden a ser encasilladas, nombradas, y en los peores casos, mercantilizadas como modelos de innovación, sin observar que dentro llevan esas marcas moderno/coloniales, esos destiempos culturales y políticos, esas desigualdades, que conviven aún en las propuestas más creativas y novedosas.

Blanchot, M. (2002). La comunidad inconfesable. Madrid: Arena Libros.

De Sousa, B. (2003). Crítica de la razón indolente. Contra el desperdicio de la experiencia. Bilbao: Desclée.

Eco, U. (1974). Tratado de semiótica general. Barcelona: Lumen.

Escobar, A. (2005). Other worlds are (already) possible: cyber-internationalism and post-capitalism cultures. En Textos de la Cibersociedad (No. 5). http://www. cibersociedad.net [Consultado: 11.5.2007].

Fernández, A. (2009). Las diferencias desigualadas: multiplicidades, invenciones políticas y transdisciplina. En Nómadas (No. 30), 22-33. 
(2008). Movimientos sociales. Una lectura a partir del posestructuralismo. En Athenea Digital (No. 14), 63-81.

Flórez, J. (2004). Una aproximación a la dimensión del disenso de los movimientos sociales: la implosión de la identidad étnica en la red "Proceso de Comunidades Negras” de Colombia. Colección Monografías (No 12). Caracas: Programa Globalización, Cultura y Transformaciones Sociales, CIPOST, FaCES, Universidad Central de Venezuela. Disponible en http:// www.globalcult.org.ve/monografias.htm [Consultado: 18.3 .2010$]$

Fonseca, A. (2009). Umbrales y metáforas en la composición de la subjetividad contemporánea. Tesis de Maestría en Educación. Bogotá: Universidad Pedagógica Nacional. Inédita.

Galcerán, M. (2009). Deseo (y) libertad. Una investigación sobre los presupuestos de la acción colectiva. Madrid: Traficantes de Sueños.

Giddens, A. (1994). Consecuencias de la modernidad. Madrid: Alianza.

Gómez, R. (2010). Procurarse sentido en la ciudad contemporánea: usos emergentes y heredados de nuevos repertorios tecnológicos entre jóvenes urbanos integrados. Informe de avance de tesis doctoral. Universidad Pedagógica Nacional. Inédita.

Guardiola, O. (2009). Los siete puentes de Könisberg. En Nómadas (No. 31), 75-91.

Haraway, D. (1995). Ciencia, cyborgs y mujeres. La reinvención de la naturaleza. Madrid: Cátedra, Universitat de València, Instituto de la Mujer.

Hermes, J. (2006). Citizenship in the age of the Internet. En European Journal of Communication (No. 21), 295-309. http://ejc.sagepub.com/cgi/content/ abstract/21/3/295 [Consultado: 20.6.2007].

Lacasa, P. (2010). Entrevista a Henry Jenkis. En Cuadernos de Pedagogía ( No 398), 52-56. Consulta on-line en

http://www.cuadernosdepedagogia.com/search.asp?idR $\mathrm{ev}=706 \& \mathrm{idEjem}=452 \& \mathrm{q}=$ Henry+Jenkins $[$ Consulta do: 02.03.2010].

Lago, S., Marotías, A., Movia, G. y Marotías, L. (2006). Internet y lucha política. Los movimientos sociales en la red. Buenos Aires: Capital Intelectual.

Larrosa, J. (2000). Pedagogía Profana. Estudios sobre lenguaje, subjetividad, formación. Buenos Aires: Ediciones Novedades Educativas.
Lazzarato, M. (2006). Políticas del Acontecimiento. Buenos Aires: Tinta Limón.

León, O., Burch, S. y Tamayo, E. (2005). Comunicación en Movimiento. Quito: Agencia Latinoamericana de Información (ALAI).

Lewkowicz, I. (2004). Pensar sin Estado. La subjetividad en la era de la fluidez. Buenos Aires: Paidós.

Lévy, P. (2007). Cibercultura. La cultura de la sociedad digital. Barcelona: Ed. Anthropos, Universidad Autónoma Metropolitana.

Martín-Barbero, J. (2005). Cultura y nuevas mediaciones tecnológicas. En AAVV, América Latina. Otras visiones desde la cultura (pp. 13-38). Bogotá: Convenio Andrés Bello -SECAB-

(2003). La educación desde la comunicación. Bogotá: Ed. Norma.

Negri, T. y Hardt, M. (2000). Imperio. Cambridge: Harvard University Press.

Rheingold, H. (1996). La comunidad virtual. Una sociedad sin fronteras. Barcelona: Gedisa.

Pérez, T. (2010). Los márgenes de la popularización de la ciencia y la tecnología. Conexiones feministas en el sur global. Informe final de tesis de doctorado. Bogotá: Universidad Pedagógica Nacional. Inédita.

Piscitelli, A. (2002). Ciberculturas 2.0. En la era de las máquinas inteligentes. Buenos Aires: Paidós.

Rueda, R. (2009). Convergencia tecnológica: síntesis o multiplicidad cultural. En Signo y Pensamiento (No. 54), 114- 130.

(2009). Cibercultura y educación: mundos que habitamos, mundos que creamos. En Magazín Aula Urbana (No. 74), 16-17.

(2008). Cibercultura: metáforas, prácticas sociales y colectivos en red. En Nómadas (No. 28), 8-20.

(2007). Ciberciudadanías: teorías y prácticas en tensión. En AAVV. Ciberamérica en red. Escotomas y fosfenos 2.0.1. Barcelona: Editorial Universidad Oberta de Cataluña-UOC.

(2005). Apropiación social de las tecnologías de la información: Ciberciudadanías emergentes. En Revista Comunicación y Tecnologías Educativas (Vol. 41), 19-33.

(2004). Tecnolocultura y sujeto cyborg: esbozos de una tecnopolítica educativa. En Nómadas (No. 21), 70-81. 
Sampedro, V. (ed.) (2005). 13-M Multitudes on line. Madrid: Catarata ediciones.

Sloterdijk, P. (2008) Actio in distans. En Nómadas (No. 28), 22-33.

Suaza, L. y Rueda, R. (2010). Cibercultura, género y política. Hacia una emergente creatividad social y educativa. En Revista Pedagogía y cultura. En prensa.

Sued, G. (2009). De la construcción de la red a sus límites: sociabilidad en Facebook. Post en el Blog del Proyecto Facebook. Cátedra de procesamiento de datos. Carrera de comunicación, UBA. En: http:// www.proyectofacebook.com.ar/de-la-construccionde-la-red-a-sus-limites-sociabilidad-en-facebook/. [Consultado 12-01-2010].

Thacker, E. (2004). Networks, Swarms, Multitudes. En Chaos theory-multimedia. http://www.ctheory.net/ articles.aspx?id=423. [Consultado 12-01-2010].
Torres, A. (2000). A natureza do poder: técnica e acão social. En Interface-Comunicacão, Saúde, Educão, Vol. 4 (No. 7), 13-24.

Valderrama, C. (2008). Movimientos sociales: TIC y prácticas políticas. En Nómadas (No. 28), 94-101.

Virilio, P. (2005). El Cibermundo, la política de lo peor. Madrid: Cátedra.

Virno, P. (2003). Gramática de la Multitud. Para un análisis de las formas de vida contemporáneas. Madrid: Traficantes de sueños.

Wajcman, J. (2006). El tecnofeminismo. Madrid: Ediciones Cátedra, Universidad de Valencia, Instituto de la Mujer. 